\title{
Making Less Vulnerable Cities: Resilience as a New Paradigm of Smart Planning
}

\author{
Francesca Moraci ${ }^{1}$, Maurizio Francesco Errigo ${ }^{2, *}$ (D), Celestina Fazia ${ }^{1}$, Gianluca Burgio ${ }^{2}$ (D) \\ and Sante Foresta ${ }^{3}$ \\ 1 DARTE Department, Mediterranea University of Reggio Calabria, 89124 Reggio Calabria, Italy; \\ fmoraci@unirc.it (F.M.); celestina.fazia@unirc.it (C.F.) \\ 2 Faculty of Engineering and Architecture, Kore University of Enna, 94100 Enna, Italy; \\ gianluca.burgio@unikore.it \\ 3 PAU Department, Mediterranea University of Reggio Calabria, 89124 Reggio Calabria, Italy; \\ sante.foresta@unirc.it \\ * Correspondence: maurizio.errigo@unikore.it; Tel.: +39-393-1756251
}

Received: 30 December 2017; Accepted: 3 March 2018; Published: 9 March 2018

\begin{abstract}
Previous studies have investigated how resilience can play a pivotal role in strategic urban design in the Netherlands and in some regional and municipal planning laws in Italy. Here, we have analysed several European projects that utilised the resilience approach successfully. Dutch policies already include resilience and climate adaptation in urban strategies. Moreover, they share those strategies with urban communities, making the innovation of the city real and cutting-edge. In Italy, on the other hand, the concept of resilience is present only in some regional laws and is still not used as an urban tool. In this paper, we aim to demonstrate how resilience can become the new paradigm of smart planning. Furthermore, we demonstrate how resilience is fundamental at all levels of urban intervention, involving municipal authorities, architects and urban planners, firms and enterprises, citizens and communities. The urban governance must establish specific goals and objectives to create a smart and sustainable city. Resilience should be one of these main aims, in order to achieve an innovative city design. A climate strategy should also be part of urban smart planning, enabling the implementation of a safer and resilient city.
\end{abstract}

Keywords: resilient urban and architectural design; smart planning; climate change; resilient regional laws; pleasant public space

\section{Introduction}

The contemporary city often fails to cope with several urban problems such as: energy inefficiency, bad performance of services and infrastructure, non-optimal waste management, misuse of land and non-renewable resources, air and water pollution, technological risk, social segregation and low safety. This failure is due not only to the complexity of the city, but also to political and technical difficulties in governance. Additionally, new methods of city construction, operation and systemic logic are needed to address the global climate change and to promote resilience and sustainable climate adaptation.

The smart city is defined as a living space varying in size and in surface area [1,2], where it is possible to deliver advanced services for citizens and for the manufacturing base, with quality of life within each community. The resilient city is an achievement of contemporary planning, which uses smart tools on cities and urban settlements to administrate and manage urban transformations to cope with climate change and the mitigation of environmental hazards. Resilience is a concept included in the meaning of the smart city and is contemplated in the paradigm of smart planning. A smart city is a result of smart planning that has resilience as one of its main aims [3-8]. 
It has already been observed how the concept of resilience plays a pivotal role in strategic urban design in the Netherlands [1]. Resilience is also present in some Italian regional and sectorial planning laws [2]. Furthermore, this innovative concept has been tested during some successful European projects such as: The Port of Rotterdam Masterplan, the implementation of the urban Climate Strategy, the "Place Leon Aucoc" project in Bordeaux [9], "Cineroleum" in London, and the research and design experimentation carried out by the research group "Arquitectos de Cabecera" of the ETSAB in Barcelona [10]. We want to show how resilience will be the new paradigm of smart planning and how this concept will involve all levels of urban interventions such as national, regional, provincial and municipal authorities, architects and urban planners, firms and enterprises, citizens and communities. All the mentioned authorities and professionals play a leading role in making a city less vulnerable; however, to pursue their common aim, it is crucial that every public and private space within a city is made available for such implementation. Hence, urban visions and strategies can be developed to achieve the creation of a more pleasant city that adapts itself to nature's transformation, creating a more pleasant environment for living.

The challenge is to link climate adaptation to other urban measures, projects and initiatives such as the management and maintenance of roads and public spaces. It is also important to develop appropriate strategies to improve awareness within the population, to promote the active collaboration of the smallest "backyard actions." To engage the community, it is necessary to ensure people are aware of the benefits they will have if they contribute to the pursuit of climate adaptation.

The approach pursued would encourage resilience and flood protection through smart planning and the guidance gleaned from the architectural and urban project. Thus, considering public space as strategic soil to develop the resilient city, using engineering technical climate defence as a new space for citizens and communities.

The theme of resilience is included in all levels of government, in municipal plans and in spatial and strategic development policies, such as in some projects concerning public and private space. The urban defence structures should bring into existence new pleasant space for the city. These actions will not only contribute to the making of a more resilient city, but they will also contribute to the creation of a more pleasant and attractive urban environment.

Often, the definition of resilience is not associated with urban planning tools. Indeed, in the literature, a gap exists between the resilience approach and resilient actions within administrative and urban governance. There is a lack of appropriate visions and strategies to enable the production of immediate effects on the main urban planning instruments for the control of urban transformations. Therefore, there is an urgent need for a scientific and pragmatic approach to the resilient city, which innovates urban planning by integrating resilience into a new and flexible smart planning tool that can manage and govern the territorial complexity.

This paper is organized in six sections: Introduction, Conceptual section, Materials and Methods, Results, Discussion, Conclusions and Implications. It starts with the description of the investigated topic and its relevance for scientific research. Afterwards, the research methodology is described, then the authors introduce some projects and some Italian regional laws to justify and reinforce the link between strategic smart planning and urban governance. In the Results section, the main achieved scientific results are reported. Finally, in Discussions and Conclusions, the main remarks relating to the scientific innovation are underlined, focusing on the perspective of future research. Experimenting in cities can achieve positive outcomes but can also reveal problems and raise questions yet to be answered. This is part of a necessary process, where learning by doing is a fundamental part of adaptive, flexible, and resilient planning.

\section{Conceptual Section}

Climate change is ongoing, and urban projects that are aware of the fragility and vulnerability of the territory must be promoted, especially in water cities [11]. Global warming is recognised and the climate will continue to change [12]. This phenomenon is mainly due to the concentration of 
greenhouse gases, leading to serious socioeconomic and ecological impacts such as ice reduction, sea level rise, alteration of hydrological systems and decreasing agricultural production [13]. Resilience can be defined as what enables survival, adaptation and thriving in the face of acute or chronic stresses [14]. Resilience typically defines a system that has the ability to maintain its core purpose despite unanticipated dangers, thanks to agility, adaptation and flexibility [15].

It is necessary to implement urban resilience actions that are able to mitigate natural risks by converting territorial problems into territorial resources and opportunities. Implementing a conscious and smart urban governance and undertaking urban awareness actions are fundamental. The aim is to create a community actively participating in promoting urban resilience policies and in creating a sustainable city [3]. The global population has grown exponentially over recent centuries [16]. More than half of all people live in towns and cities, most of which are vulnerable to climate change [17]. The densely populated and economically prosperous cities in the large river deltas that open out into the sea will be directly affected by the consequences of climate change.

However, flood safety is just one of the tasks concerning the city [18]. Indeed, climate change will also lead to more frequent periods of high temperature with consequences on citizens' health, on energy consumption, on air and water quality and on biodiversity.

A definition of urban climate resilience is provided by the Environmental Protection Agency (EPA) [19]: it is a city's ability to reduce exposure and sensitivity to, and recover and learn from, gradual climatic changes or extreme climate events. This ability comes from a city's risk reduction and response capacity, and includes retaining or improving physical, social, institutional, environmental, and governance structures within a city. The components of urban climate resilience, reflected in the conceptual framework, include three measures of vulnerability (exposure, sensitivity, and response capacity), as well as the process of initiating responsive action, learning from mistakes or ineffective responses, and building risk reduction capacity. Resilience can also be defined by resistance (precautionary measures), short-term adaptation (return to a starting point), and innovation (opportunities due to discontinuities) [20]. Vulnerability is also a major term, which, as highlighted by Sharifi et al. [21], corresponds to any characteristic or feature that makes a system susceptible to suffering from damages/disturbances. According to Denig et al. [22], vulnerability represents the propensity for a hazard to affect features. It is also defined as the condition of a community or the characteristic of a group which determine its ability or inability to cope, recover and adapt to climate change effects $[23,24]$. Resilience is a much vaguer concept and its definition has evolved-and it is still evolving-over the years. Resilience thinking has attracted attention since the Katrina disaster in 2005 [25]. Indeed, it is the ability to function, survive and thrive to any stress, according to the Disaster Risk Reduction Hyogo Protocol in 2005 [26] and to the UN conference on Disaster Risk Reduction.

The European Commission has adopted the European Adaptation Strategy with the obligation for all the Member States to implement national plans to cope with the inevitable Climate Change impacts by 2017. Many EU members have already developed national strategies, among those: The Netherlands, Denmark, Finland, Spain and United Kingdom [27,28]. Additionally, in 2012, the European Commission presented The EU Approach to Resilience: Learning from food crises, which provided policy principles for action to help vulnerable communities in areas facing crisis. Some countries, such as the UK, developed separate national resilience plans, whereas others, as The Netherlands and Denmark, included resilience in their national adaptation strategies.

Resilience, besides recovering from shocks, should also cultivate preparedness and transformative opportunities, as highlighted by Davoudi et al. [29]. According to our studies, we believe this is the most correct definition of resilience. The concept of "Planning for Resilient Cities and Regions" was developed by the Association of Collegiate Schools of Planning (ACSP, US) together with the Association of European Schools of Planning (AESOP) in 2013 and has been widely recognized by urban academia in both U.S. and EU. Often, the definition of resilience is not associated with a general urban planning tools but rather with each element that composes a city. Resilience deals with climate change by investigating the increase in temperature, desertification, the problem of floods, the intensification 
of precipitation, problems of energy efficiency and soil permeability. In this way, it will be possible to manage and govern the territorial complexity, to anticipate climate changes, and to implement an urban and territorial project. Since this resilient urban project includes both public and private areas and involves the communities, it needs specific implementation depending on different national and international contexts.

\section{Materials and Methods}

This section of the manuscript presents the general methodology used for the research. We analysed some case studies that fit in with our general objective: contributing to the creation of a resilient and safer city through a new planning approach, that considers resilience as a new smart planning paradigm.

The case studies were selected according to the following 3 characteristics:

1. Direct knowledge of the authors and active participation in some projects.

2. Presence, within the illustrated project, of an urban design based on environmental sustainability and resilience and the ability to involve citizens in the process of building a safer city, through incentives and increased awareness.

3. Elements of legislation for territorial governance aimed at highlighting the lack of a resilient approach in relation to the promotion of appropriate project.

Regarding point 1 , one of the authors experimented with resilient design techniques at the Delft University of Technology (TUDelft, Delft, The Netherlands). This experimental university course involved not only students and the administration of Rotterdam, but also citizens. All the participants were fully involved in urban transformation and project implementation activities, promoted by urban and territorial strategies (point 2).

Regarding point 3, the authors referred to both the Italian and Dutch experiences. Comparing them we were able to highlight how, in the two countries, there is a deep difference in urban governance with extremely diversified results.

In the Netherlands, the National Government, by the Provinces and by the Municipalities, support the theme of resilience. It is part of the whole system of the directives and strategies, of all the vision and all urban projects implemented in the area, producing tangible effects and results. On the other hand, in Italy, some regional laws have been updated in relation to climate change and resilience, only in recent years. However, there are no significant results neither on urban governance and management, nor within urban planning.

Some topics will be deeply analysed, such as water management, the hydraulic engineering system, the problem of energy resilience and energy performance of buildings and of open space. Special attention will be paid to those building, in Bordeaux, Barcelona and London, that can be useful again thanks to resilience.

The methodology already underlines the importance of resilience within ordinary urban planning and within the smart planning for the transformation and management of the contemporary city. A smart planning should follow the key concept of resilience, which must identify and control the behaviour and performance of different urban systems such as water, waste, buildings, public spaces, renewable systems (energy) and must integrate planning tools with social policies and economic strategies.

\subsection{Rotterdam: Urban Design for a Waterproof City}

The Netherlands is recognized as the leading country of architectural modernity, during the last two decades. Dutch architecture and urban planning are highly pragmatic and are coordinated by professionals and academics such as Rem Koolhaas and OMA, the MVRDVs of Winy Maas and the West 8 by Adrian Geuze, the Mecanoo of Francine Houben, Claus en Kaan or Coffelang BVB. Rotterdam, located between the Rotte and Maas rivers, has always stood out for its desire for progress and dynamism and its recent urban planning instruments are oriented to transform the city into a "child city" [30]. The 2010 Plan Building Blocks for a child-friendly city, with a vision to 2030, 
provides a detailed strategy for future planning based on public-private space. Buildings, public spaces, services, and infrastructures become spaces for experimentation of the creative city; the city is beginning to attract middle class families and young people, because the administration is distancing itself from zoning-based modernist planning and it is encouraging the functional urban mix. Emphasis is given by the "statement" of the Urban Vision Rotterdam 2030 [31], approved in 2007, which seeks to favour the creation of an attractive urban environment. Within this innovative vision is included the realization of a resilient city, by designing urban elements chosen for the transformation of the city, such as sidewalks, open aria, courtyards, roofs and public space.

Responsibility for water management in the Netherlands is entrusted to Rijkswaterstaat (RWS), the executive branch of the Ministry of Infrastructure and the Environment, and to the Water Control Committees. The RWS is responsible for the management of main waters (sea and rivers) and it ensures that the authorities in charge are promptly warned in the event of floods or stormy seas. Furthermore, RWS maintains dams, dunes, cages, and overvoltage barriers. It also protects the coast by regimenting and expanding the floodplains and building secondary canals. The impacts of rising sea levels due to climate change are an important and obvious concern. Currently, about $75 \%$ of the Dutch coast is protected by sandy dunes, $15 \%$ is made up of artificial constructions such as dams, and artificial barriers, while the remaining $10 \%$ is characterised by flat and very wide beaches.

Rotterdam is a great example of resilience and adaptation to climate change. Indeed, the theme of urban resilience has been under the attention of the municipality for about fifteen years. In the central districts of Rotterdam, urban retrofitting actions are experimented through new technologies and new functions applied to existing structures, in line with the climatic changes taking place. Thanks to some programs, including the "Rotterdam Climate Initiative" [1], and with the collaboration of the government, the city is engaging organizations, businesses firms, research centres and citizens, to reduce pollutant emissions by $50 \%$ by 2025 . The final aim is to adapt the city to the climate change in progress, by promoting five main initiatives based on the concept of resilience: (1) floating houses; (2) the water squares; (3) enhanced water collection systems; (4) green roofs; (5) the sustainable port.

Rotterdam is configured as the logistic and commercial centre of the European hinterland. Its port is considered as a great city resource, even though the strategic planning of the municipality is often questioning how to implement it to find the best relationship between city and port. This relationship began to change in the 80 s when, after the post-war reconstruction, the main urban problem was that the old historical city and the port were detached and the Maas river that was identified as an urban limit. Therefore, the "Rotterdam Waterfront Program" was launched to solve this problem. It considered the presence of disused industrial areas within the port zone as strategic for the city's identity.

The relationship between the port and the city is well described by Bryan Stewart Hoyle in the following diagram (Figure 1):

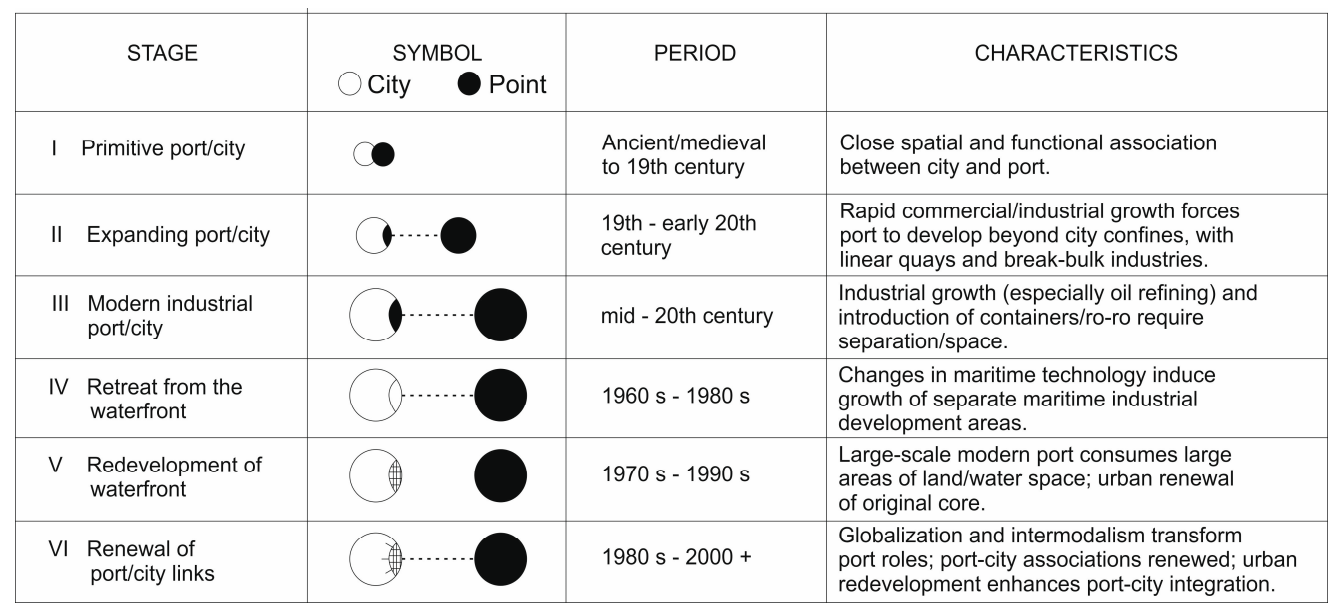

Figure 1. Different stages in the traditional port-city interface [32]. 
Figure 1 highlights the importance of the Rotterdam harbour system within urban strategies. Since the 80 s, the port has been at the centre of the urban regeneration process. The brownfields have become spaces for design experimentation for a creative and resilient city such as the area of the Kop van Zuid, the area of Rijnhaven and the area of the Old Harbour, which are considered laboratories of experimentation for the resilient city (for example the project of the Bobbing Forest or the Floating Communities...). The "Rotterdam Waterfront Program" was a proactive and audacious renovation program that managed to make the river the main centre of Rotterdam's identity. The plans designed for the port redevelopment have been characterised by a sophisticated mechanism of understanding the territorial specificity and they aimed at creating spaces highly usable as public place.

Currently, the "Rotterdam Climate Change Adaptation Strategy" is ongoing with the aim of further implementing both the port and the entire city centre. The city administration understood the need for a resilient urban project that will make the city completely safe and responsive to climate change by 2025 . Rotterdam is already structurally protected by a primary flood defence system consisting of dunes along the coast and by dams along the rivers. There are also many flexible barriers that can be closed to protect the city in case of need. Within the dam system, there are many polders meant to drain excess water through the channels and an additional system of secondary dams that protect the inland areas from flooding. An ingenious hydraulic engineering system keeps the city safe from flooding. The polder, on which the city was built, consists of a set of dams (such as the Maeslant storm surge barrier) and a system of drainage and pumping channels that have protected the urban system for centuries, ensuring its resilience.

This strategy, known as "moving to the rhythm of the city," will not only affect the inhabitants of the city but also, universities, consortia and all the companies in Rotterdam. The strategy indicates that there is still time to adapt to climate change, so that it is now possible to link adaptation to other urban strategies and to spatial development projects. Hence, management and urban areas maintenance will be improved.

To design the strategy, the city of Rotterdam was divided into six zones: the port area, the Stadshaven, the outer dyke, the inner dyke, the compact city and the neighbourhoods built at the end of the Second World War. The main difference between these six zones is that they are either defended by the dykes (inner dyke) or they are lacking them (outer dyke). In other cases, the main difference is the presence/absence of potential public spaces: if on one hand some areas have available space, on the other hand there are dense industrial areas limiting the feasibility of the public space project.

The protection of the city from floods is the main priority of the climate strategy. Particular attention is paid to those areas mostly exposed to risk, as the port, and to some other strategic infrastructures. In the most populated areas with the highest building density, some projects will be carried out on public space, such as water squares. Water storage capacity will be increased through the regulation of city's canals, moreover the permeable surface will be increased with more green areas and less paved ones. A "blue and green" strategy will be then implemented which will also contribute to make the urban environment more attractive and enjoyable.

Rotterdam's climate adaptation strategy is based on some actions to optimize the water defence system. Firstly, improvement of urban resilience through adaptive measures on the urban environment. Finally, agreement between all urban stakeholders, regarding climate adaptation as a strategy that can innovate the city. The strategy gives close attention to some key actions as safety, flood-proof construction, floating buildings (for instance the Rijnhaven project), water-based public spaces that increase the resilience of the system. The climate strategy is part of the whole smart planning of the city, because all visions, recommendations and advice become part of the urban planning allowing the implementation of a safer and resilient city.

The water squares, the green roofs, the increase of canals' flow and section, are strategic elements to increase urban resilience. These actions contribute to the water levels maintenance of the Schie and Rotte rivers, preserving the area from flooding. Some other specific actions are planned, to increase the resilience in the Merwe-Vierhavens dam, in Rozenburg and in some parts of the IJsselmonde. Moreover, 
the dams of Hoek of Holland and Maasboulevard will also have to be reinforced. The construction of new dams for the protection of Rotterdam could also be envisaged, in addition to the existing ones.

The group of architects "De Urbanisten" has defined several projects for the management of urban water in Rotterdam and in neighbouring polders, realizing several water squares. The Benthemplein water square is an interesting example: it is a large multifunctional water square that combines rainwater collection with the creation of an outdoor public area. The project was defined after three preparatory workshops in which the natural elements and the form of public space were discussed (Figure 2).

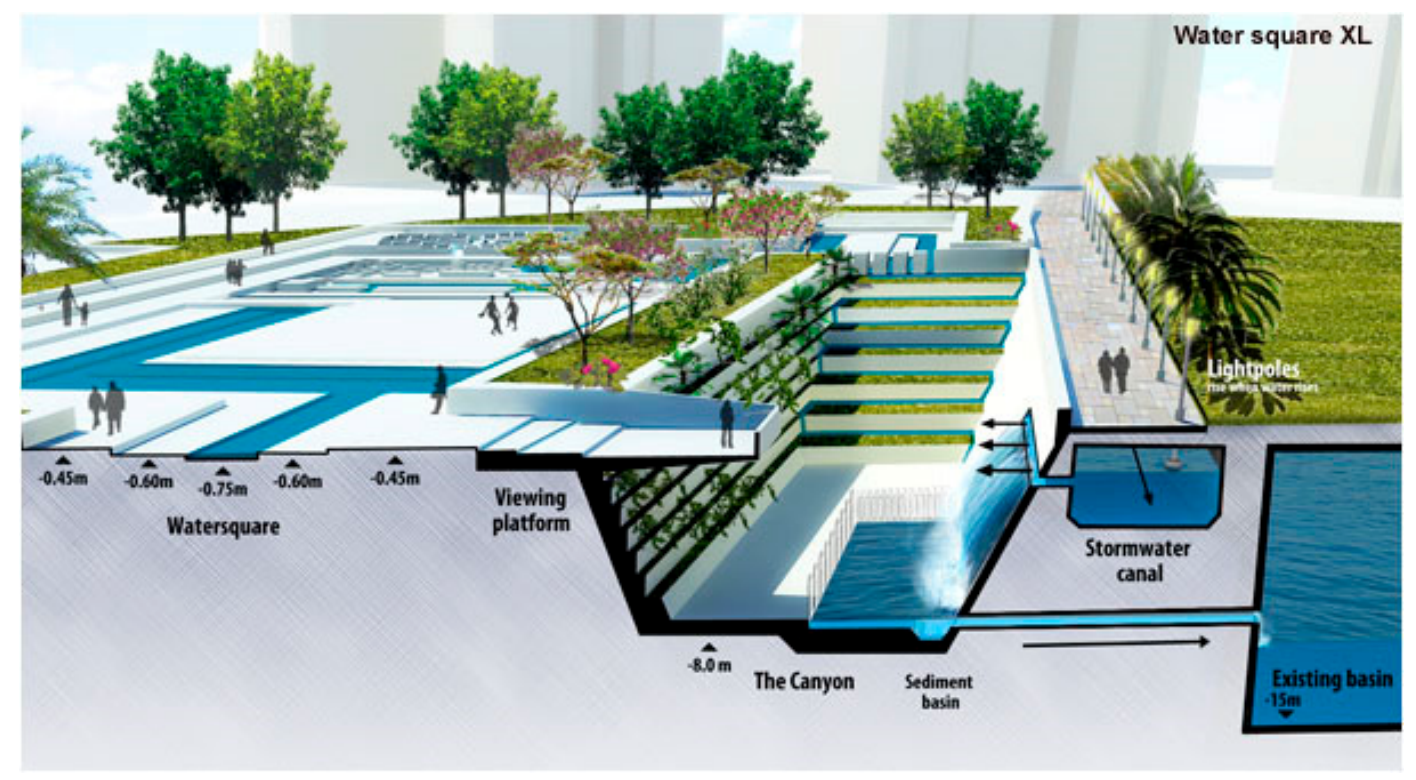

Figure 2. Water square XL in Rotterdam. Resilient Urban Design. De Urbanisten [1].

The areas for water accumulation within the city must also be strengthened, increasing the canal section and implementing new channels and small lakes for the stagnation of water. There is the need to reinforce the blue lines within the city and connect them to the urban water system with a reticular perspective.

\subsection{Energy Resilience in the Rotterdam Port Project}

Resilience is also linked to energy performance of buildings and open space. Indeed, in every resilient strategy there is a clear plan which aims to reduce energy consumption and to optimise the use of renewable resources. According to the European strategic plan, policies on infrastructure networks and transport play a decisive role in achieving the purpose of smart, sustainable, and inclusive growth. Particularly, the plan states that these policies aimed at "reducing greenhouse gas emissions by at least $20 \%$ compared to the 1990 levels, [...] bring the share of renewable energy sources to $20 \%$ and improve energy efficiency by $20 \%$." In line with the implementation of the growth objectives of the European strategy, the European Commission presented the Connecting Europe Facility initiative package aimed at supporting investments for infrastructures in the transport, telecommunications, and energy sectors [33]. This led to the establishment of a detailed regulatory framework that will strengthen and emphasize the central role of ports as nodal points of the European commercial and transport system. Moreover, it will enhance the potential of European seas and oceans and coastal regions, solving the economic problems affecting the maritime sectors. Another European priority is increasing the competitiveness of the port system, which will be implemented by upgrading port infrastructures and equipment that need to be in line with the best environmental, energy and operational standards. Considering that, since 2000, the maritime trade has intensified with an annual average rate of change 
of $3.5 \%$, a positive change of $0.7 \%$ compared to that recorded between 1970 and 2000 and that several of the world's major ports saw a growth in traffic. The maritime sector is the only one characterised by both sectoral integration dynamics and supply chain logics, with investments made by parties outside the transport world mainly.

The relationship between energy, transport and infrastructure is of great interest, since multiple environmental sustainability aims can be pursued via feasible innovative solutions: emissions reduction, energy consumption reduction, measures to cope with climate change. The state of the art confirms that the trend in sustainable development of port-cities, is to invest in energy related sectors and activities. Stimulating the production of energy from renewable sources is the priority for Europe [34].

The new REN21 Report [12] shows that renewables have grown by $135 \mathrm{GW}$ of new capacity, marking an increase of $8.5 \%$ over the previous year, worldwide. In the last decades, the world economy has grown without a rise in $\mathrm{CO}_{2}$ emissions, despite the $1.5 \%$ increase in world energy consumption. According to the same Report, Italy has positioned itself at the top of the world rankings. In 2017, onshore and offshore wind energy globally added around 46.6 GW to the energy supply. It is expected that wind power will increase about $17 \%$ by 2030 . Unfortunately, offshore-which have interesting advantages in terms of reducing the energy impact-haven't taken off yet in Italy. In recent years, the Italian southern coast has been interested by more than 15 projects of wind farms, but the approval process is often complex. In Europe, on the other hand, offshore wind farm installations are on the rise and projects are planned to produce further $26.4 \mathrm{GW}$ capable of meeting $4 \%$ of the energy demand, thanks also to the continuous technological and production improvements of this sector.

Therefore, Italy is not in line with the European development of resilient cities. Most of European cities invest on projects to improve the energy efficiency and to innovate their ports. Among these projects, we can mention the Ostende for "Haliade 150" (the largest offshore wind turbine) and Rotterdam for the "Dutch WindWheel" (a self-sufficient hi-tech mill in terms of energy and "smart" control units). However, some Italian examples are noticeable for their innovative strategies; Taranto for the first off-shore shipbuilding company and Civitavecchia for the project of an "electrified quay" that guarantees energy efficiency and optimization of port services. The feasibility, size and extent of the projects do not depend on the territory or the port in whose waters the plants are inserted, but on other factors. The difficulties in choosing offshore energy in Italy reside in the perplexity regarding the environmental compatibility of the plants with birdlife and fish species, the noise generated by commercial or military shipping routes, etc.

From the state of the art of European experiments, interesting results emerge in terms of reduction of impacts, but also of possible economic repercussions of the installation of fish farming and tourist facilities $[35,36]$.

\subsection{Vision 2030 for the Port of Rotterdam: Maasvlakte 2, the Sustainable Extension}

The development path of the most important European harbour for the next twenty years has already been elaborated: it is presented in the Vision 2030 program. The main points concern environmental sustainability and access to the hinterland. The central aspects of the program are the environmental sustainability and resilience, which correspond to increased production efficiency and the use of second-generation biofuels, including those produced from algae and enzymes. The production of electricity in the seaport will be increased as well through renewable sources, such as biomass, solar and wind energy. Concerning the territorial development, Vision 2030 aims mainly at developing connections with the hinterland. These will be guaranteed both by computer systems for traffic management and by new infrastructures, such as the Blankenburg tunnel and the A4-Zuid road.

Nowadays the port of Rotterdam is the largest in Europe: Maasvlakte2 is its last extension, the project will increase the capacity of the port accommodating ships for the commercial transport of 18,000 containers. The city of Rotterdam, which rapidly grew after the Second World War, thanks to 
the progressive reduction of trade barriers among the Member States of the European Union, today is the physical, commercial and economic reflection of its port.

Another novelty regarding the port of Rotterdam is the construction of 800 electric cabins that can supply up to 5000 boats.

The onshore power provision plan at dock, supplying the port of Rotterdam with safe energy, has been completed recently. This plan will allow an overall reduction of $\mathrm{CO}_{2}$ emissions and a decrease in the concentration of nitrogen oxides and particulates, with significant progress in reducing air pollution.

Ports consume tens of millions of kWh every year and for this reason funds have been allocated to activate interventions aimed at reducing drastically the thousands of tons of harmful emissions per year by encouraging the production of energy from renewable sources.

It is therefore necessary:

- to identify the problems related to the development of offshore wind energy;

- to succeed in combining territorial vocations (availability of different primary sources-not only wind energy, localization of consumption) with the technologies available to optimize production, consumption and distribution of energy.

A recent Enea study shows that Italy has an undisputed potential: "the Adriatic region has an average potential of $2 \mathrm{kWh} / \mathrm{m}$, on the western coast of Sicily it is up to $5 \mathrm{kWh} / \mathrm{m}$, while on the western coast of Sardinia it reaches $10 \mathrm{kWh} / \mathrm{m}$." This implies recognising the potential of clean energy, in all its forms, for the coastal territories of the EU, "harnessing this energy could contribute to the energy autonomy of the islands and peripheral maritime regions." From the point of view of resilient planning, the port area of Rotterdam is extremely vulnerable to environmental hazards, as it extends for more than $40 \mathrm{~km}$, is located in the outer dyke belt and is directly connected to the river Maas and to the North Sea. The latest expansion of the Maasvlakte project includes roads built at the same height as the dams, so they will keep operating even in adverse conditions. A good strategy, like the climate strategy experienced in this area, should preserve the port area through the use of marine protection systems and the creation of some safety zones, shelter areas, in order to secure ships and goods at times of emergency.

\subsection{Resilient Urban Projects}

The current conditions of a large number of western cities have challenged not only the idea of a type of progress and continuous development of modernity, but also the disciplinary instrumentation of the architectural project, which cannot avoid considering the needs of the real contemporary urban areas.

The damage caused by the crisis in the last decade has given rise to a series of actions based on the social need to conceive spatial transformations, at different scales, according to participatory and inclusive criteria. In Europe, an increasing awareness has been developed by citizens and several architects who have chosen to "listen" to the city. Plato, in his "Republic," claimed that the city is like a pasture- "a place influencing and feeding its inhabitants" life" - therefore, if it were well cared for, citizens would live in an environment perceived as a common good.

Three main practices are being investigated in different areas, providing the opportunity to reflect on the most up-to-date issues of the architectural debate. The main idea is that the designers often work with the resilience of the architecture and of the public space, so architects can give a new opportunity and another use to the buildings. These three original approaches to the architectural design are substantially based on the resilience of the city and its architecture, both from an academic and a professional point of view, considering the applied methodologies and the results obtained (which reflect the changing conditions of the current architect's actions).

These innovative experiences prove that the theoretical instrumentation of architecture is not always able to grasp the meaning of the current structural reality. From this perspective, it is necessary to rethink the disciplinary tools: if "theory is a toolbox" [Deleuze], then a new cognitive system must 
be developed to analyse current phenomena. Otherwise they might be interpreted as marginal with respect to the 'classical' readings which the architectural literature has just started dealing with.

Based on these considerations, this work suggests an interpretative approach viewing architecture — and, more generally, the built and transformed environment—as a patient who must be listened to and whose symptoms may reveal possible pathologies. The architectural project seeking an inclusive methodology and dialogue, instead of imposing determined solutions and strategies, takes into account urban needs and takes advantage of all areas of daily life, of ordinary and infra-ordinary spaces, of the urban interstices and of the remaining infrastructural zones showing a certain degree of resilience.

Since the end of the last century the need for a careful use of the resources available has emerged, consequently the architects have paid more attention to the resilience of the buildings, that is, the capacity they have to be useful again. Giving buildings a second chance, extending their lives, is not a new idea: the reuse and recycling of architecture have been known since ancient times. However, in an ecological vision of the world, a constructed building is a resource that should not be lost and, in fact, should be reintroduced into the life cycle of the cities. The construction of a new architecture has an important Ecological Footprint, while it is very low in an existing building.

The interventions manipulating and transforming the space are joined by others opening a positive reflection, namely the zero degree of architecture, or rather, those cases showing no architectural intervention in the forms usually known. The case of Place Léon Aucoc in Bordeaux, in this sense, is very significant and illustrative: the architects Lacaton and Vassal in 1996 were commissioned, within a municipal plan of urban embellishment, to redesign Léon Aucoc square. An article published a few years later in the Spanish newspaper, El País, Iñaki Ábalos, describes the attitude of the two French architects towards the Bordeaux authorities' request, simply quoting their answer: "We would prefer not to." Lacaton and Vassal suggested non-intervention, stating that: "The square is already beautiful. As a project, we've proposed to do nothing apart from some simple and rapid maintenance works (replacing the gravel, cleaning the square more often, treating the lime trees, slightly modifying the traffic) to improve the use of the square and to satisfy the locals" [5].

After visiting the places and talking with the inhabitants of the neighbourhood, Lacaton and Vassal decided that the best thing that could be done for that square-which in their opinion and that of the inhabitants was already beautiful like that-was to abstain from transformation. According to French architects, the square is a resilient space, therefore one must know how to exploit its potential to reactivate its use. Lacaton and Vassal proposed a very light "care" program: continuous maintenance, a little extra cleaning and some adjustments here and there. This is one of the few cases in which the architect retracts, refusing to put a signature as a guarantee of Quality Architecture: the city and its space in many cases work thanks to the relational balance between the citizens and the spaces in which everyday life can freely flow.

Since 2013 the School of Architecture of Barcelona (ETSAB) has started an interesting educational path, establishing a working group that connects the school to the city to experiment design solutions for architectural regeneration. Arquitectos de Cabecera (General Architects working like General Practitioners) is a team of architects and architecture students founded in 2013 at the ETSAB. They work, along with other professionals, on the 'care' of dwellings, immersing and integrating themselves in critical realities. The basic idea of the AC is that the architect, as a professional of proximity, must take care of the people who live in those places and the relations they have with the architectural space.

The idea proposed by Arquitectos de Cabecera opens, in our opinion, towards a new possible area of the architect's profession. In the wide range of possibilities and professional opportunities, in addition to large real estate transactions and infrastructure projects, there is an ample field of work consisting in interventions working on the resilience of buildings. These actions that range from simple maintenance to structural or energy rehabilitation, from the reorganization of the domestic space to the change of use of the buildings and to the care of the public space. In short, a set of architectural and urban opportunities requiring an architect's skills. 
In recent years, the young students, led by their teachers (Ibon Bilbao and Josep Bohigas), have experienced the possibility of responding to the specific needs and urgencies of the inhabitants of the Raval neighbourhood, which is the most disadvantaged part of the historical centre of Barcelona. The young architects, working as competent technicians with a global vision of the problems at stake, listen to the needs of the patients, represented by the inhabitants and the buildings, in order to propose possible solutions [6].

Another interesting example of architectural resilience is the project carried out by an architectural collective, the Assemble Studio based in London, which since 2010 has been working on urban and architectural regeneration through participatory methods.

The Cineroleum project (realised in London in 2010) consists of the conversion of an abandoned petrol station into a cinema. The experiment derives from the reflection made by the Assemble Studio on the large number of petrol stations in disuse throughout the United Kingdom (more than four thousand). Considering this, the London team has experimented with the reconversion of this infrastructure, located in Clerkenwell Road in London, involving about a hundred citizens who have worked hard to create the cinema.

The "new" cinema changes radically the perception of a place that used to be a mere infrastructure without any particular quality. The intervention of the Assemble Studio and the citizens of London who created Cineroleum, with a very contained action, has prolonged the existence of an obsolete and abandoned urban element, giving it dignity and a new life.

\subsection{Urban Resilience in the Italian Regional Laws}

Urban resilience is commonly understood as the ability of a territory, of a city and of a community to prevent and "resist" some environmental and social matters (natural disasters, changes in climatic conditions, physical, social, economic degradation phenomena in urban areas [4]), in a proper way.

What is the proper application of a resilient approach to planning on an urban and territorial scale?

A resilient city is an urban system that does not confine itself to adapting to climate changes (in particular to global warming which, in recent decades, have made cities increasingly vulnerable with ever more dramatic consequences and enormous costs). The resilient city modifies itself by constructing new social, economic and environmental responses that will allow it to resist the stress of the environment over the long term. Another definition of "resilient city" refers to "the ability of a system to plan for, prevent, resist, adapt to, or recover from adverse impacts."

Resilience is therefore today a necessary component for sustainable development acting, first of all on the governance and management models of urban systems. Hence a sustainable city is a resilient city. The concept of resilience is associated with the climate change produced by our society. The effects mainly concern the built environment. The risk of exposure to natural phenomena can no longer be considered an eventuality, on the contrary, under certain conditions, it becomes an urban constant, as experienced by the inhabitants of Genoa and of many other Italian cities often dealing with the devastation of the floods.

In New York, the occurrence of Hurricane Sandy marked the beginning of the reflection on the shape of the city that should take into account its possible changes based on the space gained by water at every atmospheric event. In this scenario, since some urban sectors can be considered as permanently submerged, it may be cheaper to surrender to the presence of water, rather than investing large amounts of public money to resist it [13].

The following are some significant models referred to Italian regional laws on urban and regional planning. The new Regional Urban Law of Emilia-Romagna in the Organizational Technical Arrangement (DTO No. 8/2017) indicates, in a nutshell, that the objectives of the regional urban reform are: "to increase the attractiveness of cities with urban regeneration policies, enriching the services and strategic functions, environmental quality, resilience to climate change, seismic safety, etc."

Article 34-Strategy for urban and ecological environmental quality-states: "The PUG (the municipal urban plan), through the urban quality and ecological environmental strategy, pursues 
the goal of improving the attractiveness and competitiveness of the urban centres and the territory, upgrading the settlement and environmental quality. This will be achieved through the growth and qualification of services and technological networks, the quantitative and qualitative increase of public spaces, the enhancement of identity, cultural and landscape heritage, the improvement of environmental components, the development of sustainable mobility and the increase of the resilience of the housing system related to the phenomena of climate change and seismic events."

The Urban Planning Law of Tuscany within article 62-Quality of settlements-outlines some indications about energy containment performance of buildings and urban blocks, with reference to energy containment, resilience, usability and safety.

In Chapter I, Title VIII (Rules for sustainable construction)-Article 217 (Sustainable construction-Purposes and public actions), the law gives these indications: "The Region encourages environmental sustainability and energy saving in the construction of public and private buildings, as well as urban regeneration interventions." In Chapter III, Title V, inspired by the principles of the eco-district, indications are given to pursue energy self-sustainability through the integrated use of renewable sources, resilience to climate change, a rational management of resources, the use of low-carbon technologies and multimodal sustainable mobility systems.

In Calabria, within the Regional Law 5 August 2016, No. 28, the following is added: "To promote plans and programs of Urban Regeneration aimed at the redevelopment of significant parts of cities and urban systems to preserve the territory, a mooring of urban fabric without attractiveness that satisfies the housing needs within the existing urban perimeter, creating economies of scale."

These plans and programs must guarantee social inclusion, quality of life and urban resilience. The Regional Council, following the proposal of the Councillor for territorial and urban planning, approves an operational guidance document defining the implementation modalities of the aforementioned plans and programs of "Urban regeneration," the rules of which the local authorities will comply with.

Particularly significant is the ten-point document of the ANCI (National Association of Italian Municipalities) on the resilience of cities.

With a view to resilient systems, it is necessary to start from municipal civil protection plans. In fact, while the national, regional and provincial plans focus mainly on other civil protection aims, the municipal plans are addressed directly to the citizens. The ANCI has long imagined a New Civil Protection System, which invests on the role of the City, of the Metropolitan City and of the Mayor, enhancing the principle of subsidiarity, awareness and participation of citizens. This means implementing concrete projects, such as the establishment of a National Civil Protection Day, the establishment of special territorial conferences, and the use of the civil service for the promotion of projects on risk mitigation activities. In this context, the "Making resilient cities programme" can be the starting point to build a new civil protection beginning with local communities.

The 10 points to guarantee the resilience of a city are:

- Ensure that within the local administration a coordination structure is set up to identify and reduce the risk of disasters, based on the participation of citizen groups and on alliances with the civil society. Ensure that all sectors of the administration are aware of their role in reducing the risk of disasters and are ready to take action.

- Allocate specific resources to reduce the risk of disasters and give economic incentives to homeowners, to low-income families, to firms and to the community investing in risk reduction.

- Maintain an up-to-date system of data on local risks and vulnerabilities, carry out risk assessments and take them into account in plans and decisions on urban development.

- Ensure that the information and urban resilience plans are easily accessible to the public and have been publicly discussed.

- Invest in resilient and sustainable infrastructures that help reduce risks, ensuring maintenance and necessary adaptations to climate change. 
- Check the safety of all schools and health facilities and adjust them if necessary. Introduce and apply appropriate risk criteria in building regulations and land use planning.

- Identify, where possible, safe land to be allocated to low-income citizens and develop regeneration programmes for unregulated settlements.

- Ensure the implementation of risk reduction training courses and education programmes; protect ecosystems and areas that naturally act as prevention, mitigating the effects of flooding and other intense weather events to which the city is vulnerable. Adapt to climate change through effective risk reduction actions.

- Implement local monitoring programmes concerning preventive alert systems and emergency management plans, involving citizenship.

- After each disaster, ensure that the needs of the victims are placed at the heart of the reconstruction matter and that civil organizations and the people damaged are directly involved in the definition of solutions.

\section{Results}

The authors analyse the issue of urban resilience through a few of the best practices that have been successfully tested in some European areas. The resilience is declined with particular attention to the topics of water and energy efficiency in the Rotterdam's case study, regarding the building design in Bordeaux, Barcelona and London, and from the normative point of view and urban strategies, offering an overview of the Italian and Dutch case studies. But resilience is also present in every project regarding public space aiming at adapting territories to contemporary climate changes, making cities less vulnerable and mitigating environmental hazards.

The comparison among the practices mentioned above shows that in the Netherlands a deep attention is paid to the strategic aspect of urban planning. In the Dutch policies resilience is considered as part of the appropriate urban strategies promoted by municipalities and it is shared with all urban stakeholders. Furthermore, climate adaptation assumes the role of a real urban strategy that can innovate the city, making it more fascinating and modern.

Rotterdam's climate adaptation strategy is based on specific actions taken to optimize the water defence system, for instance the improvement of resilience through adaptive measures to be implemented throughout the urban environment. This strategy shows great attention to some key actions, such as safe district systems, flood-proof construction, floating buildings (the Rijnhaven project), or water-based public spaces that increase the resilience of the system.

Public areas have been planned in order to store rainfall that will be used to irrigate urban green spaces. The storage capacity of underground water will be improved, collective water gardens will be implemented, mostly in the common private areas and the green roofs will allow the storage of the rainwater. The Dutch case study clearly proves that resilient and defensive urban design actions are contained within appropriate urban planning policies and instruments. Currently the structural reinforcement of dams and of the water defence systems are under the responsibility of the Ministry of Waterways and Public Works. From the point of view of cooperation, it is desirable to involve provinces, municipalities, private companies, universities, research centres and citizens in the process of the implementation of all the actions conceived to increase urban resilience.

Additional areas of water storage are included in the projects that are currently being implemented in Rotterdam, for example in Centraal Station or in Kruisplein and also in the urban visions 2030 or 2050 as "Rotterdam child friendly city" or "Wilderness school playgrounds." Strategic initiatives, such as "Moving to the rhythm of the city" and "Green Team. Paving out, Plants in "contain resilient concepts." The creation of a waterproof city requires both individual approaches to the problem and intensive cooperation among water boards, the ministry, the municipality, urban developers, private companies, housing corporations and, above all, the direct involvement of the citizens. It is absolutely essential that everyone contributes to implement the strategy devised for the creation of a resilient city. 
The approach pursued throughout the manuscript aims at fostering resilience and flood protection by means of the architectural and urban projects. Moreover, it considers the use of the public areas as strategic spaces where the resilient city can be developed, employing engineering technical climate defences as new public zones for citizens and communities.

Resilience topics are included in all levels of government, in all urban planning instruments and in strategic development policies concerning public and private space. As far as the defences become everyday-life spaces for the city, this will not only help make cities more resilient but also create a more enjoyable urban environment.

In all the mentioned urban projects, architects and urban designers are finally responding to the threats of the rising sea levels by "welcoming the water" into the city. Water has become a resource, an opportunity and the "leitmotiv" to reuse and regenerate communities and the public space of the contemporary city.

\section{Discussion}

The projects illustrated in this manuscript belong to the category of urban transformation plans that seek to respond to climate change, trying to contribute to the formation of a resilient contemporary city, capable of adapting to the environmental transformations. A city that is waterproof, energy performed and equipped with suitable urban governance tools. A city that has adopted smart planning and the resilient concept in all sectors that drive urban transformation.

If the meaning of "Smart City" in its complexity includes Smart Economy, Smart People, Smart Governance, Smart Mobility, Smart Environment, Smart Living, we are requested to develop-working in close collaboration with public and private entities that operate on the territory-a platform design, a set of actions that aim at making cities "smart." This can be achieved producing high technology tools, reducing energy consumption, promoting clean transport and improving the overall quality of life of all citizens. The prospect of smart cities involves thinking of urban organisms that produce a better management from their own internal capacity, mobilizing technology and behavioural resources, which will make the urban environment more sustainable and more attractive. The environmental virtuosity has to be a common element of all the smart and resilient cities. Smart planning should, therefore, represent the heart of the process of developing and implementing a local strategy. It should provide solutions tailored to fit the local context, identifying specific areas, appropriate tools, implementing parties and leaders in order to create smart cities for smart communities. Smart planning following the key concept of resilience has to map, identify and control the environmental behaviour and performance of buildings. It should integrate strategies for bioclimatic buildings and for renewable systems. Regarding the water, a smart planning must integrate water management planning with political, economic and social strategies to promote a more effective use of water, involving all stakeholders within the integrated management. It has to optimize industrial consumption through a policy of reduced pollution, while diminishing the waste produced by the distribution improving the infrastructures. It also needs to analyse and evaluate the problems of efficiency, water quality and the danger of floods representing a significant threat to the sustainability of cities. Smart planning must engender an improvement of urban governance involving a top-down (managed and promoted by national and local entities) and bottom up approach (arising from the needs of the population and city users). It should improve the role of citizens in the achievement of the objectives defined by themselves. Finally, it must provide a specific platform to facilitate the sharing of knowledge [4-8] and stimulate the dialogue for the development of skills and innovation.

The state-of-the-art on these governance challenges has already been extensively reviewed by Deakin [37] as a retrospective on the research undertaken, reported on and disseminated under the SmartCities project (http:/ / www.smartcities.info/).

Smart planning becomes a laboratory-zip, a strategic and operational interface between "content" and "container." The principle of efficiency is the foundation for planning and performance, upon which the agenda of all resilient cities is based, while the principle of conservation of energy is the 
basis of the civilised behaviour of all citizens. For this reason, the smart and resilient city must link the "instances of the city" and must transform the detractors of urban quality (together with the problems incidental to every urban reality) into new requirements for quality and performance. It must deal with the rapid extension of the residential, industrial, commercial and tourist districts, furthermore, it must develop energy efficiency and climate change defence strategies using appropriate tools.

A smart city must also be up to the challenge of increasing its competitiveness, identifying new forms of service and innovative management models, in relation to the types of activity needed for an efficient use of the resources available. Smart planning is the new model for the integrated planning of the smart city, that is not completed within the standards and codes, but it also means building the "owned" idea of the city, the management of its implementation while monitoring the environment data [3-8].

A waterproof city needs individual actions in addition to cooperation among water boards, ministries and municipalities, urban developers and private firms, housing corporations and, overall, the citizens. It is extremely important to include the resilience theme in all levels of government, in all urban planning instruments, in spatial and strategic development policies. This way the key factor will be to develop a new vision of the public space and of safe communities.

Urban governance is the best place to establish goals and objectives that must be pursued for the creation of a resilient city [5-37]. The city must be a unique, resilient project and every part of it, both public and private, must be seen as a potential space in which to pursue climate adaptation policies. To make smart planning implementable and equip it with the new paradigm of urban resilience, all levels of government and all the stakeholders must be involved. The resilient city is an urban challenge, but it is also a political and economic challenge.

Making the city resilient means, as shown in the Netherlands, anticipating environmental risks and to encompassing them within the planning domain. It also implies constructing an urban planning as a unitary design able to lead to tangible results and to the creation of a desirable, less vulnerable city for smart citizens.

\section{Conclusions and Implications}

The city is the most complex and typical socio-ecological system shaped by human beings. Currently, however, the vulnerability of the city is often the occurrence of a variety of uncertain perturbation factors, which have caused tremendous economic, social and cultural losses. In this context, the concept of rational urban development is based on discussing urban resilience and urban sustainability. In the process of realising the goal of both sustainable and resilient development, the dominant role of social factors must be taken into account. Thus, compared with the simple investment of manpower and materials, the establishment of an urban rational development mechanism could help the urban capability cope more effectively with the various possible crises.

The Sustainability Science highlights the essential role of socio-political infrastructures in urban resilience. Sustainability fundamentally deals with the normative decision process involved in steering a system to an upgraded state, whereas resilience emphasizes a system's capacity to resist disturbance and shocks. Efforts to integrate both resilience and sustainability into urban planning require tools that capture, quantify, and visualise how stakeholders' preferences, social relations and political influence interact to affect urban vulnerabilities. The concept of "Smart Cities" is increasingly dominating the debate about the future of urban environments. As more and more cities rush to embrace this concept, Smart City projects are rapidly outpacing the policies governing their development. While Smart City projects present remarkable opportunities for municipalities to modernise their operations and improve efficiency and cost-effectiveness, these projects also introduce a range of security challenges.

Incorporating risk management at the outset of planning improves the ability of Smart Cities to ensure long-term resilience, both in developing new projects and in maintaining and operating existing components. Resilience planning builds the partnerships and information sharing frameworks needed to prepare for new challenges in the dynamic world of Smart Cities. It helps support the analysis 
and assessments required to have a comprehensive situational awareness of the new capabilities, the interconnections among them, and the emerging risks that Smart Cities are confronted with. Moreover, it makes it possible to build resilience capacity throughout the Smart City and its systems. Experimenting in cities can produce positive outcomes, but it could also raise problems and questions yet to be answered. This is a part of a necessary process, where learning by doing is a fundamental part of adaptive, flexible and resilient planning.

Urban planning for enhanced resilience and sustainability is ultimately a complex social and political process. Urban resilience efforts must involve social and political forces. Engaging local communities in city planning is vital in building a society that can sustain resilience consistently. Rotterdam itself provided an interesting example of working cooperation with local communities, where the city worked with citizens and households collaborated to promote local sustainability initiatives. Rotterdam has used a neighbourhood approach as a basis for action, focusing on the needs and desires of the Rotterdammers. Creating a waterproof city, as Rotterdam's best practice shows, requires intensive cooperation, public awareness and citizens' engagement: everyone is deeply involved in making the city waterproof.

The Rotterdam Adaptation Strategy (City of Rotterdam, 2013) charts the course by which Rotterdam has planned to adapt to the consequences of climate change and shows how residents, businesses and the city can gain maximum benefit by it. This strategy offers the framework and the guiding principles for a future-proof development of Rotterdam and ensures that every spatigress will include subjects such as flood management, accessibility and robustness of the city as basic principles from the very outset of the process.

It is also important to link defence design with other spatial planning tools, to allow a better integration and implementation, a fair cost reduction and an increased innovation.

Rotterdam practice, in its adaptation strategy, focuses on anticipating climate changes.

The main innovations are that:

- the strategy encourages flood protection through the architectural and urban project;

- the resilience theme is included in all levels of government, and in all urban planning instruments, and spatial and strategic development policies. This means that resilience is a fundamental paradigm of smart planning;

- as a waterproof city, Rotterdam has involved in its strategy both individual actions and cooperation among water boards, ministries and municipalities, urban developers and private firms, housing corporations, but above all, the citizens.

- Rotterdam is developing smart planning and resilience concepts at school. The Dutch education system is one of the best in the world and aims at raising children's awareness so that they can refine their behaviour with growth and be examples of best practices and smart communities.

- the defence works become spaces for the city and new high quality public areas, thanks to the "blue and green" strategy which will also contribute to making the urban environment more attractive and enjoyable.

In Rotterdam, architects and urban designers are finally responding to the threats of rising sea levels by "welcoming the water" into the city, so that the waterscape is becoming a new paradigm of spatial planning. Rotterdam is striving to become a climate proof city that will be safe and attractive to inhabitants, visitors and businesses even in the future. It is conceived as a healthy delta city where it is pleasant to live, work and spend leisure time. Rotterdam is becoming resilient not just by strengthening its defences against climate changes and rising seas, but also by building a more cohesive and inclusive society. Resilience thinking is being incorporated in the policy-making and in the initiatives across all domains of the city government, including social, physical and economic programmes.

Through the different case studies, the authors want to contribute to the construction of an urban methodology that can allow the construction of a resilient urban system. The methodological innovation must take place by means of three priority actions: 
- Regulatory innovation. It is necessary to include the issue of resilience within the aims of urban and regional regulation in the short and medium term; the technical legislation must indicate, as shown in the selected case studies, the appropriate strategies and incentives for its implementation in the urban project.

- Governance strengthening. We need to implement the urban governance in order to allow the strategic disciplinary integration for the implementation of the resilient urban project. A governance that is able to elaborate strategies shared with the communities. Urban governance is the best place to achieve goals and objectives that must be pursued for the creation of a resilient city [5-37].

- Implementation of Smart Planning. It is the strategic tool for the implementation of the resilient project. The smart Planning, elaborated following the key concept of resilience, should, therefore, represent the heart of the process of creating a resilient urban system, challenging climate change and any other human or natural risk. Smart planning must foster an improvement of urban governance allowing the involvement and integration of a top-down (managed and promoted by national and local) and a bottom up approach (arising from the needs of the population and city users). The resilient city is an urban challenge, but it is also a political and economic challenge; making the city resilient means anticipating environmental risks and to encompassing them within the planning domain.

Author Contributions: Francesca Moraci conceived and wrote Sections 1, 4 and 5; Maurizio Francesco Errigo conceived and wrote Sections 2, 3.1 and 6; Celestina Fazia conceived and wrote Sections 3.2 and 3.3; Gianluca Burgio conceived and wrote Section 3.4; Sante Foresta conceived and wrote Section 3.5. Maurizio Francesco Errigo harmonized the contributions, bringing them back into a research paper; Francesca Moraci supervised the manuscript. The manuscript was produced through contributions of all authors. All authors have approved the final version of the manuscript. The English structure and fluency were revised by two professional proof-readers (Daniela and Paola Labarbuta) and by a native English speaker (Ingrid Giordano).

Conflicts of Interest: The authors declare no conflict of interest.

\section{References}

1. City of Rotterdam. Rotterdam Climate Change Adaptation Strategy; Rotterdam Climate Initiative: Rotterdam, The Netherlands, 2013.

2. Russo, M. Urbanistica per Una Diversa Crescita. Progettare il Territorio Contemporaneo; Donzelli: Rome, Italy, 2014.

3. Moraci, F.; Fazia, C. Le città smart e le sfide della sostenibilità. TeMA J. Land Use Mobil. Environ. 2013, 6, 35-45. [CrossRef]

4. Giffinger, R.; Kramar, H.; Haindl, G. The Role of Rankings in Growing City Competition. In Proceedings of the XI EURA Conference, Milan, Italy, 9-11 October 2008.

5. Hollands, R. Will the real smart city please stand up? City 2008, 12, 302-320. [CrossRef]

6. Caragliu, A.; Del Bo, C.; Nijkamp, P. Smart cities in Europe. J. Urban Technol. 2011, 18, 65-82. [CrossRef]

7. Komninos, N.; Pallot, M.; Schaffers, H. Special issue on smart cities and the future internet in Europe. J. Knowl. Econ. 2013, 4, 119-134. [CrossRef]

8. Lombardi, P.; Giordano, S. Evaluating the European smart cities visions of the future. Int. J. Anal. Hierarchy Process 2012, 4, 27-40. [CrossRef]

9. Ruby, I.; Ruby, A.; Steiner, D. Naive architecture: Notes on the work of Lacaton \& Vassal. In Lacaton E Vassal, 2G; Editorial Gustavo Gili: Barcelona, Spain, 2002; Volume 21, pp. 4-19.

10. Bohigas, J. Quaderns d'Arquitectura i Urbanisme; Arquitectos de Cabecera (AC): Barcelona, Spain, 2016; no. 266. Available online: http:/ / quaderns.coac.net/es/2016/02/arq-de-capcalera/ (accessed on 22 December 2017).

11. Galderisi, A.; Ferrara, F. Enhancing urban resilience in face of climate change: A methodological approach. TeMA J. Land Use Mobil. Environ. 2012, 5. [CrossRef]

12. Intergovernmental Panel on Climate Change (IPCC). Summary for policy makers. In Climate Change 2014: Synthesis Report; Pachauri, R.K., Meyer, L.A., Eds.; Contribution of Working Group I, II and III to the Fifth Assessment Report of the Intergovernmental Panel on Climate Change; IPCC: Geneva, Switzerland, 2014.

13. European Environment Agency (EEA). Climate Change, Impacts and Vulnerability in Europe 2012; EEA Report no. 12/2012; Office for Official Publications of the European Union: Luxembourg, 2012. 
14. The Rockefeller Foundation. Cities Taking Action: How the 100RC Network Is Building Urban Resilience; Georgetown Climate Center's Adaptation Clearinghouse: Washington, DC, USA, 2017.

15. Chappin, E.J.L.; van der Lei, T. Adaptation of interconnected infrastructures to climate change: A socio-technical systems perspective. Util. Policy 2014, 31, 10-17. [CrossRef]

16. Eger, J.M. Smart growth, smart cities, and the crisis at the pump a worldwide phenomenon. I-WAYS J. E-Gov. Policy Regul. 2009, 32, 47-53.

17. Newman, P.; Beatley, T.; Boyer, H. Resilient Cities: Responding to Peak Oil and Climate Change; Island Press: Washington, DC, USA, 2009.

18. Sennet, R. Why Climate Change Should Signal the End of the City-State; The Guardian: London, UK, 2014.

19. United States Environmental Protection Agency (EPA). Evaluating Urban Resilience to Climate Change: A Multi-Sector Approach. 2017. Available online: www.epa.gov/research (accessed on 18 December 2017).

20. Guenther, B.; Mitchell, T.; Polack, E.; Tanner, T. Urban Governance for Adaptation: Assessing Climate Change Resilience in Ten Asian Cities; Institute of Development Studies: Brighton, UK, 2009.

21. Sharifi, A.; Yamagata, Y. Major Principles and Criteria for Developing an Urban Resilience Assessment Index. In Proceedings of the 2014 International Conference and Utility Exhibition on Green Energy for Sustainable Development (ICUE), Pattaya, Thailand, 19-21 March 2014.

22. Denig, S.; Stevns, M.; Cook, S.; Frost, L.; Friedberg, A.; Tolkoff, L. Toolkit for Resilient Cities: Infrastructure, Technology and Urban Planning; SIEMENS: Munich, Germany, 2013.

23. Wilson, G.; Kelly, C. Community Resilience and Land Degradation: Evidence from the EU LEDDRA Project. In Proceedings of the LEDDRA RGS/IBG International Conference, London, UK, 31 August-2 September 2011.

24. Giordano, F.; Mascolo, R.A. State of the Art Review: Guidelines, Adaptation Strategies and Plans at Regional and Local Level; Assisting Communities Together (ACT): Geneva, Switzerland, 2010.

25. Johnson, D.L. Service Assessment Hurricane Katrina August 23-31, 2005; NOAA's National Weather Service: Silver Spring, MD, USA, 2006.

26. International Strategy for Disaster Reduction. Hyogo Framework for Action 2005-2015: Building the Resilience of Nations and Communities to Disasters. In Proceedings of the World Conference on Disaster Reduction, Kobe, Hyogo, Japan, 18-22 January 2005; United Nations Inter-Agency Secretariat of the International Strategy for Disaster Reduction (UN/ISDR): Geneva, Switzerland, 2007.

27. Swart, R.J.; Singh, T. MEDIATION and the Adaptation Challenge: Identifying Appropriate Methods and Tools to Support Climate Change Adaptation Decision Making; Wageningen UR: Wageningen, The Netherlands, 2013.

28. Biesbrock, R.; Swart, R.J.; Carter, T.R.; Cowan, C.; Henrichs, T.; Mela, H.; Morecroft, M.D.; Rey, D. Europe adapts to climate change: Comparing National Adaptation Strategies. Glob. Environ. Chang. 2010, 20, 440-450. [CrossRef]

29. Davoudi, S.; Brooks, E.; Mehmood, A. Evolutionary resilience and strategies for climate adaptation. Plan. Pract. Res. 2013, 28, 307-322. [CrossRef]

30. City of Rotterdam. Rotterdam, City with a Future: How to Build a Child Friendly City; Bernard van Leer Foundation: The Hague, The Netherlands, 2010.

31. City of Rotterdam. Rotterdam Urban Vision: Spatial Development Strategy 2030; Rotterdam Municipality: Rotterdam, The Netherlands, 2008.

32. Hoyle, B.S. The redevelopment of derelict port areas. Dock Harb. Auth. 1998, 79, 46-49.

33. Moraci, F.; Fazia, C. Impacts of renewable energy on landscape. Alternative of offshore wind in marine areas. TRIA Int. J. 2013, 145-156. [CrossRef]

34. Meyer, H. City and Port. Urban Planning as Cultural Venture in London, Barcelona, New York and Rotterdam: Changing Relations between Public Urban Space and Large Scale Infrastructure; International Books: Utrecht, The Netherlands, 1999.

35. REN21. Renewables 2017 Global Status Report; REN21 Secretariat: Paris, France, 2017.

36. Legambiente. L'assurdo Stop all'Eolico Off-Shore in Italia; Legambiente: Rome, Italy, 2015. Available online: https://www.legambiente.it/sites/default/files/docs/eolico_off-shore_dossier2015.pdf (accessed on 18 December 2017).

37. Deakin, M. Smart Cities: Governing, Modelling and Analysing the Transition; Routledge: Oxon, UK, 2013.

(C) 2018 by the authors. Licensee MDPI, Basel, Switzerland. This article is an open access article distributed under the terms and conditions of the Creative Commons Attribution (CC BY) license (http:/ / creativecommons.org/licenses/by/4.0/). 